\title{
Electricity reform in Europe: towards a single energy market
}

Jean-Michel Glachant and François Lévêque (ed.)

Reviewed by Basudeb Chaudhuri

Centre de Sciences Humaines, Delhi, and University of Caen, Normandy, France

International Journal of Regulation and Governance 10(1): 59-62

This important volume of essays is the outcome of a European project titled 'Sustainable Energy Specific Support Assessment (SESSA)' that aims to create a well-functioning internal electricity market in the European Union (EU).

In the foreword, Paul Joskow states, "I believe that the ultimate goal of electricity liberalization initiatives should be to create new governance arrangements for the electricity sector that yield longterm benefits to society, by increasing the efficiency with which electricity is produced and consumed, in ways that are consistent with environmental goals and policies. These benefits are to be realized by relying on competitive wholesale markets for power to provide better incentives for controlling construction and operating costs of new and existing generating capacity, to encourage innovation in power supply technologies, and to shift the risks of technology choice, construction cost, and operating 'mistakes' to suppliers, and away from the consumers." Also, effective liberalization programmes will still leave a significant portion of the total costs of electric supply - distribution and transmission - subject to regulation. Accordingly, reforming traditional regulatory arrangements governing the distribution and transmission networks has, generally, been viewed as an important complement to the introduction of wholesale and retail competition to supply consumer needs.

The above two statements set out the overall agenda of the book with great clarity. Joskow also presents the main elements of restructuring the 'grammar' of policy. Among these, vertical separation of competitive segments such as generation, marketing, and retail supply from regulated segments such as distribution, 
transmission, and systems operation are considered necessary to guard against cross subsidization between competitive and regulated activities. Ensuring horizontal competition in the generation segment, to prevent abuse of market power in wholesale markets and to ensure competitive efficiency, along with horizontal integration of transmission and network operations to ensure geographic cover and network efficiency, is also stressed. The foreword, by one of the world's leading specialists on law and economics, lays emphasis on the transparency and independence of regulatory mechanisms and institutions to realize the full benefits of both competition and regulation in the areas of production, distribution, and pricing. It is pointed out that restructuring of wholesale markets and transmission systems in the electricity sector should be carried out prior to tackling the problems of retail prices. The EU had paid inadequate attention to the problems of horizontal market power that affect prices in wholesale markets, as compared to the US. We also learn that in the US, unlike the EU, there is no general law to mandate retail competition. It is left to the individual states to organize. Another major point raised - important for emerging economies - is that organized wholesale energy markets alone may not provide sufficient incentives for investment in new generating capacity. Given standard regulator constraints on pricing; security of supply; and competition, that are imposed on companies, long-term contractualization may be necessary to ensure adequacy of investment. The necessary connection between gas and electricity generation is also analysed.

In their introductory chapter (Part I), Glachant and Lévêque analyse the internal electricity market in the EU in a period (20042008) when national compulsions in situations of crises often put into question the progress of convergence in market and regulatory mechanisms across member states. In considerable detail and with a textbook presentation of their case, the authors present i) the necessity of improving market design in the member states; ii) improving EU's internal market design; iii) coping with EU industry structures; iv) improving the transmission and Transmission Systems Operator (TSO) governance; and v) improving regulatory governance. A list of priority and secondary actions is presented in a 20-point layout at the end of the chapter (page 31). Some of the priority actions, that apply in any market context (in particular in all federal systems) are 'balancing services', like having competitive energy trading markets in the very short term, interconnections 
and grid management, market surveillance, regional cooperation of TSOs, and regional harmonization.

David Newbery's chapter 'Refining market design' continues the 'policy grammar' on competition and regulation started by Joskow, Glachant, and Lévêque. To cite the chapter (p. 35, paragraph 1), " the goals of market design include, as a precondition of continued popular and therefore political support, confidence in security of high quality supply at sustainable competitive prices. Sustainability here refers both to the ability of the sector to finance and deliver efficient and reliable electricity supply and in the environmental sense of reducing greenhouse gas emissions. Efficiency requires that energy, capacity, and ancillary services are at least cost, but at prices that allow adequate investment to be financed by the private sector. This in turn requires that markets provide price signal entry of new generating capacity that is efficient in location, timing, scale, and fuel choice, and for dispatch that minimizes social costs, including environmental costs. Market integration, in turn, means that European costs are minimized, and trade takes place guided by comparative advantage, importing competition into more concentrated markets". It seems quite obvious that in any regional block such as the EU or even in a federal polity, several of these conditions would be difficult to realize. Glachant and Lévêque have already pointed out that the reduction of diversity of market conditions in the EU was a difficult political task, especially given the penchant of many countries for promoting 'national champions'. Overcoming regional disparities and institutional differences require both goodwill and protracted negotiations as European examples have often shown, and Newbery presents a wide variety of European examples to highlight both the diversity of methods and institutions by which reforms in the energy sector took place in Europe.

In Part II of the book, along with Newbery's chapter, Lars Bergman deals with the question of industry restructuring and market power, previously raised in the opening chapters in greater detail. This chapter elaborates the idea of 'workable' competition and 'best practices'. Barriers to workable competition in the European context are discussed, such as national monopolies or ill-designed regulations (weak environmental regulations are a notorious example). Market power, as measured by the price cost margin, is discussed (this is developed in much greater detail in a technical chapter by Yves Smeers in part III of the volume). Part II also develops the question of regulation harmonization in Europe 
(Hope and Singh), which has always been, and relatively successfully, an example of gradualism rather than the 'big bang' approach to reforms. This is understandable, given European diversity and the necessity of generating consensus on reforms. Other chapters in part II analyse European enlargement and its difficulties (von Hirchhausen and Zachmann), investing for sustainability (Pèrez Arriaga and Barquin), and policy assessment (Green et al). Europe, which at this point of time is undoubtedly the region of the world that is most concerned and has the most elaborate policy framework for addressing sustainability, wants to put this issue at the top of the international political agenda. The arguments for this are laid out in this chapter in an essentially normative framework. Since these arguments are generally well known, we will not repeat them further. Suffice it to say that the social dimension of sustainability, notably the access of the poor to energy, is also addressed, which is a problem even in the European context given the overall cost structure of sustainable power generation, and it is stressed that market solutions alone cannot solve the problem of access.

The last part of this book are three studies that do an indepth technical analysis of the European electricity market-the measurement of market power, mentioned above; EU integration of New Member States electricity markets, and their price convergence using econometric tests (Zachmann); and long-term scenarios for strategic energy policy (Capros and Mantzos). I believe that longterm scenarios, and this is not a reproach of the authors concerned here in particular, never adequately take into account all possible evolutions that may occur in emerging and developing countries in the medium and long term in their industrial development, and this remains the Achilles' heel of long-term scenario modeling.

Overall, to conclude this review, I would like to stress the extraordinary quality of the analysis and the in-depth review of European successes and failures in electricity reform. It is difficult to be critical of this volume as it is a perfect example of both European scholarship, in-depth research, and the competitive conditions that generate such research! 